\title{
Research on Communication Command Network Architecture Based on Ship-Shore Integration
}

\author{
Huang Jinfeng ${ }^{1, a}$, Zhao Fuzheng ${ }^{1, b}$ \\ ${ }^{1}$ China Ship Development and Design Center, Wuhan 430064, China

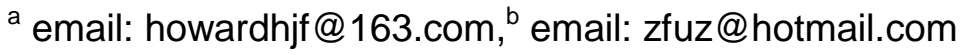

Keywords: Ship-Shore;SW Communication;Formation;Network Architecture

\begin{abstract}
With the deepening of the official ship information construction, the building of communication command network architecture becomes one of primary tasks. A summary and review about some core elements about satellite communication, HF network and communication networks for ship formation was given. Based on the functional and performance requirements analysis of the confidentiality, practicability and integration of communication command network, the communication command network architecture of ship shore integration was made. At last, a preliminary design was finished.
\end{abstract}

\section{Introduction}

Because of the needs of safeguarding state's marine rights and interests, China is steadily enhancing its ocean power and reinforces safeguard system of middle and remote enforcement. Then, we should achieve waters' communication coverage by improving overall communication command gradually, which will provide the support for maintaining maritime interests. As a very important part of ocean equipment power, communication command network should become a collaborative system of ship and shore.

\section{Demand Analysis}

After analyzing communication command network at home and abroad, and considering the actual demand of maritime police for communication command at now and future, following rules in maritime police communication command network should be took into account.

\section{Integrated Construction}

Base on the characteristic of maritime police communication command law enforcement and other tasks, in order to realize communication command information integrated reliable and confidentiality, safeguard maritime police communication command task successfully accomplished, integrated service、 multi-communication method should be integrated constructed. So, a short wave connected short and sea 、formation communication on sea vairborne communication connection 、 satellite communication、BeiDou Navigation Satellite System should be combined and construct a comprehensive、 effective、 confidential modern communication command system[1].

\section{Confidentiality}

Confidential communication method should be used in communication command system, so that the system could encrypt and decode the information automatically, and prevent communication command information form intercepting and monitoring, realizing internet safety protection and identity authentication.

\section{Practicability}

In order to adapt complex using environment of maritime police ship, the communication command system should be constructed highly integration. The machine should meet following 
requirements: easy operation 、 performance stabilization 、 environment adaptability 、 communication reliability.

\section{Information Transfer}

Short wave net support information transfer between center commander、 sea section commander center、sea commander center and slipway, including sound message、facsimile、E-mail and other confidential information. Maritime formation communication information system support the transformation of sound message 、 facsimile 、 HD video and other confidential information between slipway and airborne platform[2].

\section{Formation Communication}

Maritime formation should keep communication command channel clear. Confidential digital sound、SMS、MSS 、 facsimile and video are all included. Formation communication system should meet following requires: support communication during moving; support confidential communication, it can prevent hostile forces from monitoring intercepting, and can keep communicating at any weather and any season[3].

\section{Communication Command System Framework}

\section{Communication Command Business Organizational Management Framework}

Communication command business organizational management framework of China ocean equipment is shown in Figure1. Communication command network could be divided into four communication command hierarchy based on the administrative level. First is General Command Center. Second are sea area command center. Third is formation command center on sea. Last is ship. Every local command centers are guided and managed by three sea area command center.

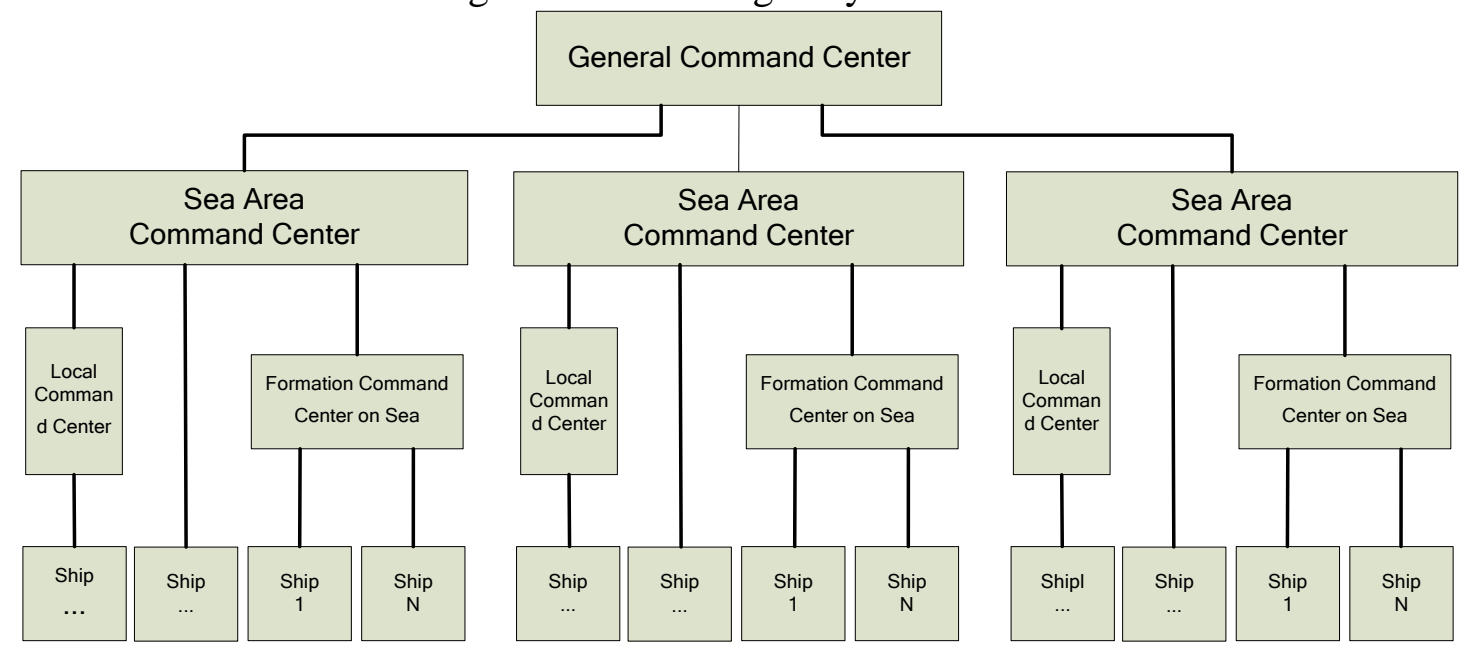

Fig.1. Communication Command Business Organizational Management Framework

\section{Description of Network Overall Framework}

Descripting by communication method constitution and network system construction as figure 2.

Description by communication method of constitution network[5], the whole communication system construction could be divided into four parts: The first is shore broadband transport networks, it can realize the interconnection among different command center in land mainly by optical fiber wed and telephone network. The second is shore sea satellite access networks, command center on sea could connect into every level command center by satellite earth station based on this. The third is shore sea shortwave access network, support connection for sea command center、 slipway and every level command center mainly based on the short wave connection website. The fourth is sea formation communication network, build a local wireless network to guarantee the business transmission among formations based on the VHF and UHF frequency radio band[6,7]. 


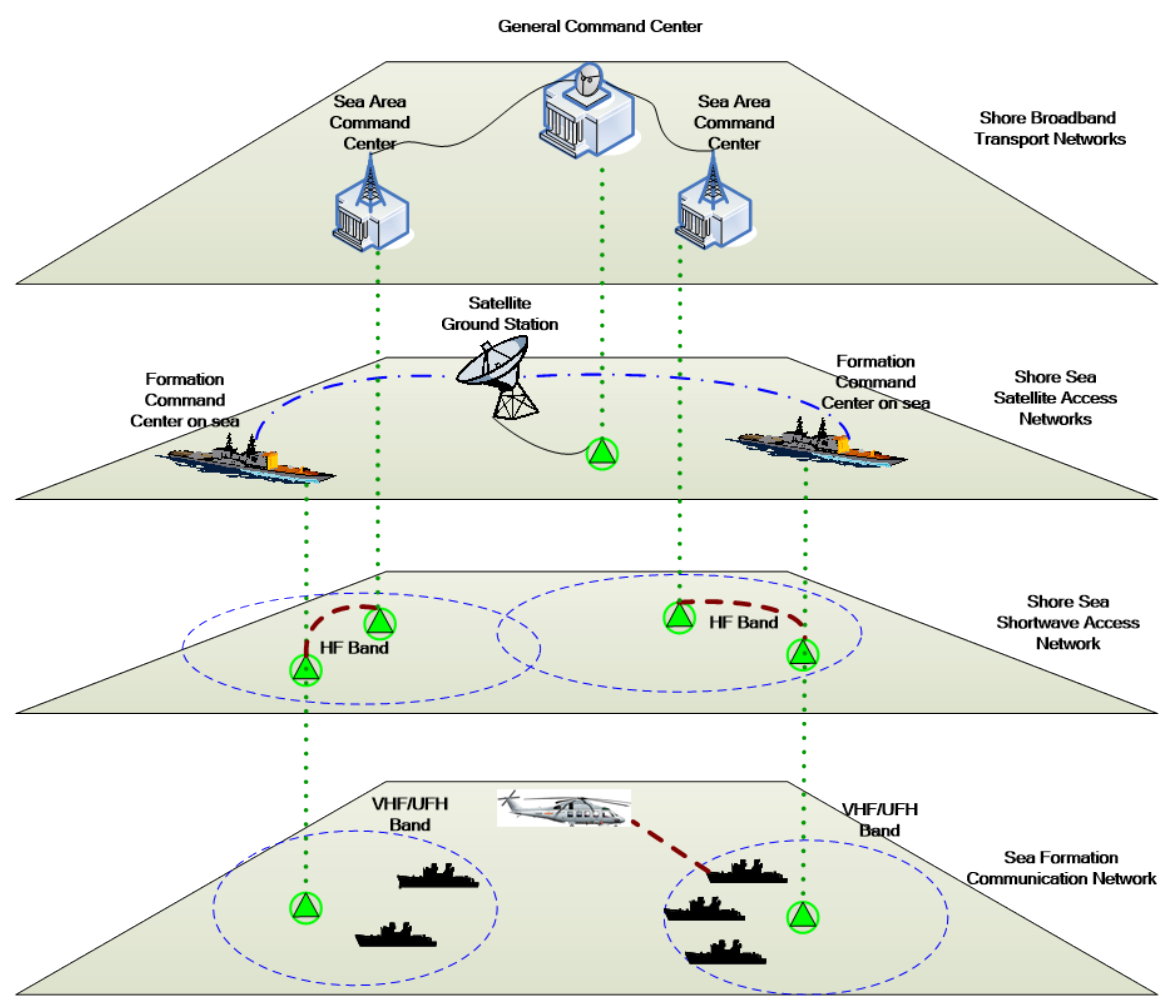

Fig.2. System description based on the different communication methods

\section{The General Technical Scheme}

\section{The Overall Design of Network Management}

The network management system adopts an two-level architecture, namely the total network management center and the sea area network management center, and the total network management equipments are deployed in the command center (namely the primary network management center), and the system has sea area network management equipments (namely the second level network management center), as shown in figure 3.

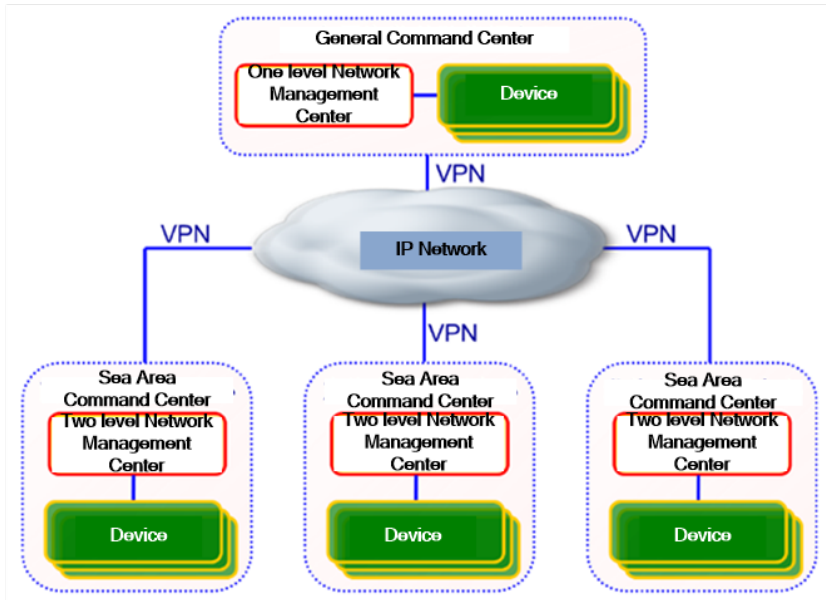

Fig.3. The Network Management System

The two-level network management center is connected by the VPN constructed on the private network, to manage and control the network establishing, the operation planning, the network adjustment, the monitoring control, the frequency sending, the authentication of user and the service security of command centers at all levels. 


\section{The Design of Network and Information Security}

\section{The Design of Network Security}

The design adopts the way of separating the users from the core network to ensure the network security, as shown in figure 4 . The full network can be divided into four layers, namely the business layer, the access layer, the adaptation layer and the core layer, and the function and role of each layer is described as follows:

A.The business layer: to provide network users with application service.

B.The access layer: to provide network users with the access to network service, including shortwave access, VPN access and LAN access.

C.The adaptation layer: to provide users with the adaptive service of various kinds of business and signaling by agency, including the voice, message and e-mail, and separate the users from the core network simultaneously.

D.The core layer: to provide the network operations with all core services, including SIP service, e-mail service, distributed storage and so on.

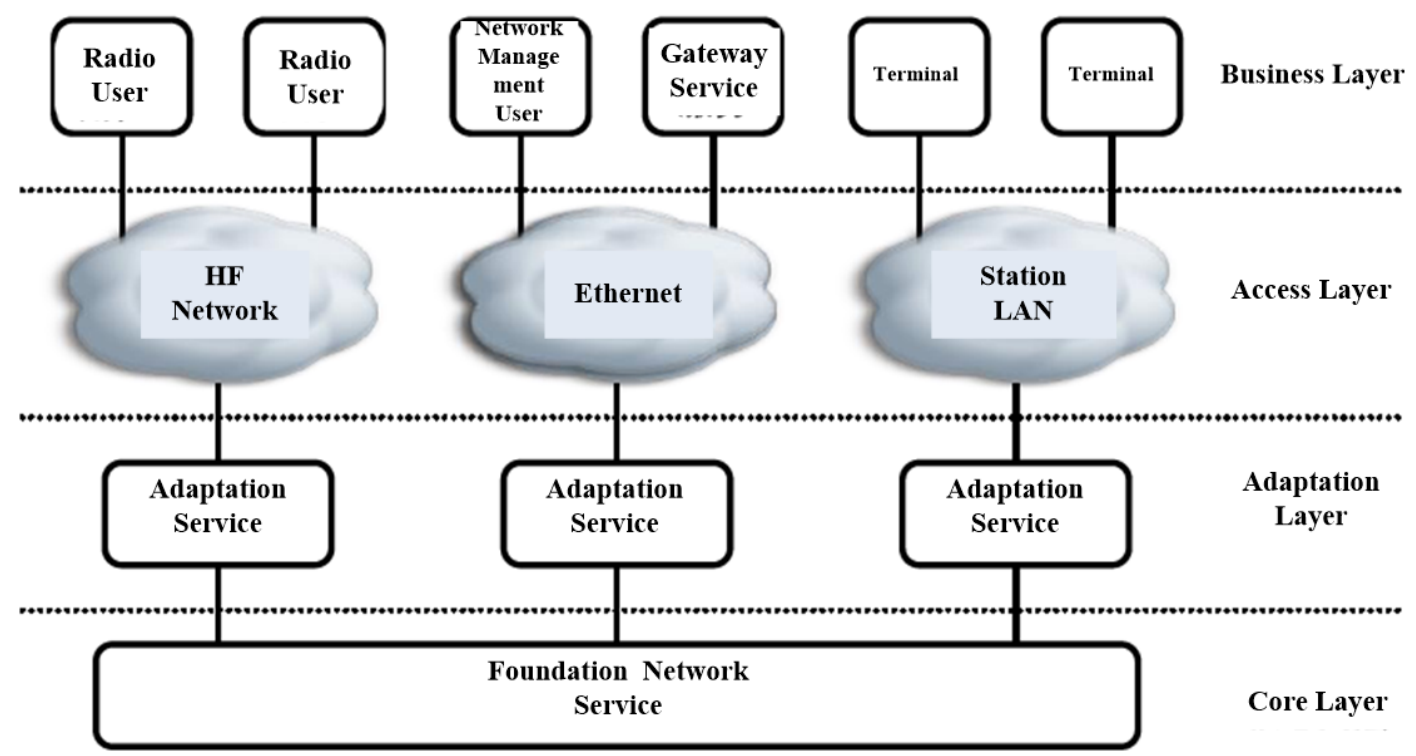

Fig.4. the architecture of network security

The full network adopts the PKI system to certify the legitimacy of users' status, and on this basis we adopt the symmetric key system to certify the users' e-mail messages by digital signature. The network security management system can be divided into three layers: the primary security management system, the secondary security management system and the node-level security access of control equipment, as shown in figure 5.

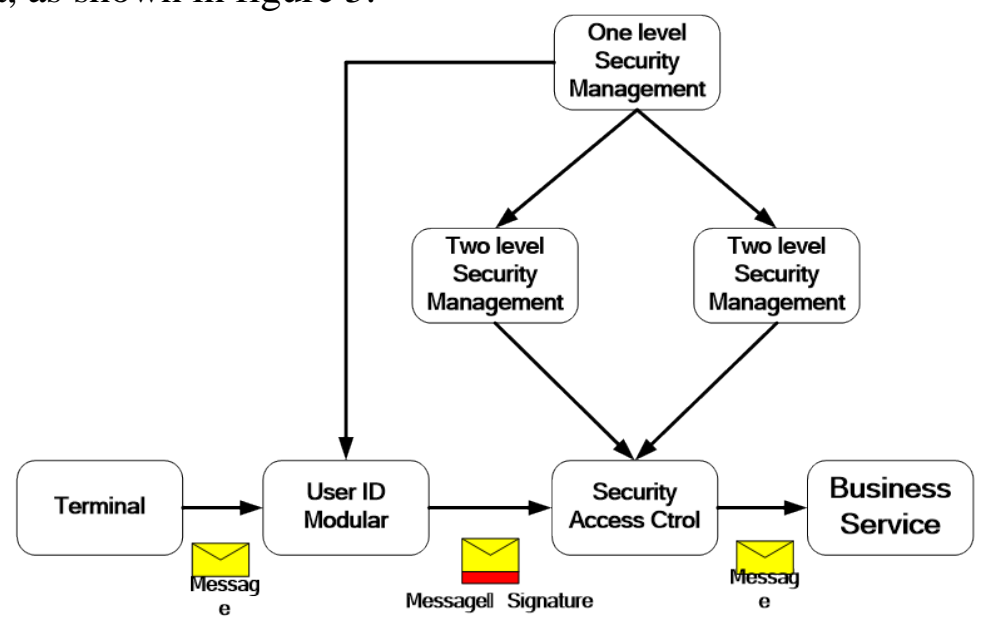

Fig.5. The Security Architecture Of Network Service 


\section{㶦 The Design of Information Transmission Security}

The transmission of information security and privacy from two aspects, as follows:

A.Transmission channel security: By time-efficient, automatic line protection measures to ensure the safety of the transmission channel, the so-called channel encryption.

B.The transmission of information encryption: In communication, using the digital processing technology to pretreat the service information, like voice, SMS, email and fax, then use the provisions of the state of special security module for automatic encryption processing, and then to transfer.

\section{Shortwave Shore Access Network}

Shortwave shore access network is set according to the present organization structure, as shown in Figure 6, the network is composed of the commander Center, the three major sea command center, provincial / city command center and shortwave shore station and slipway and IP bearing network, etc.

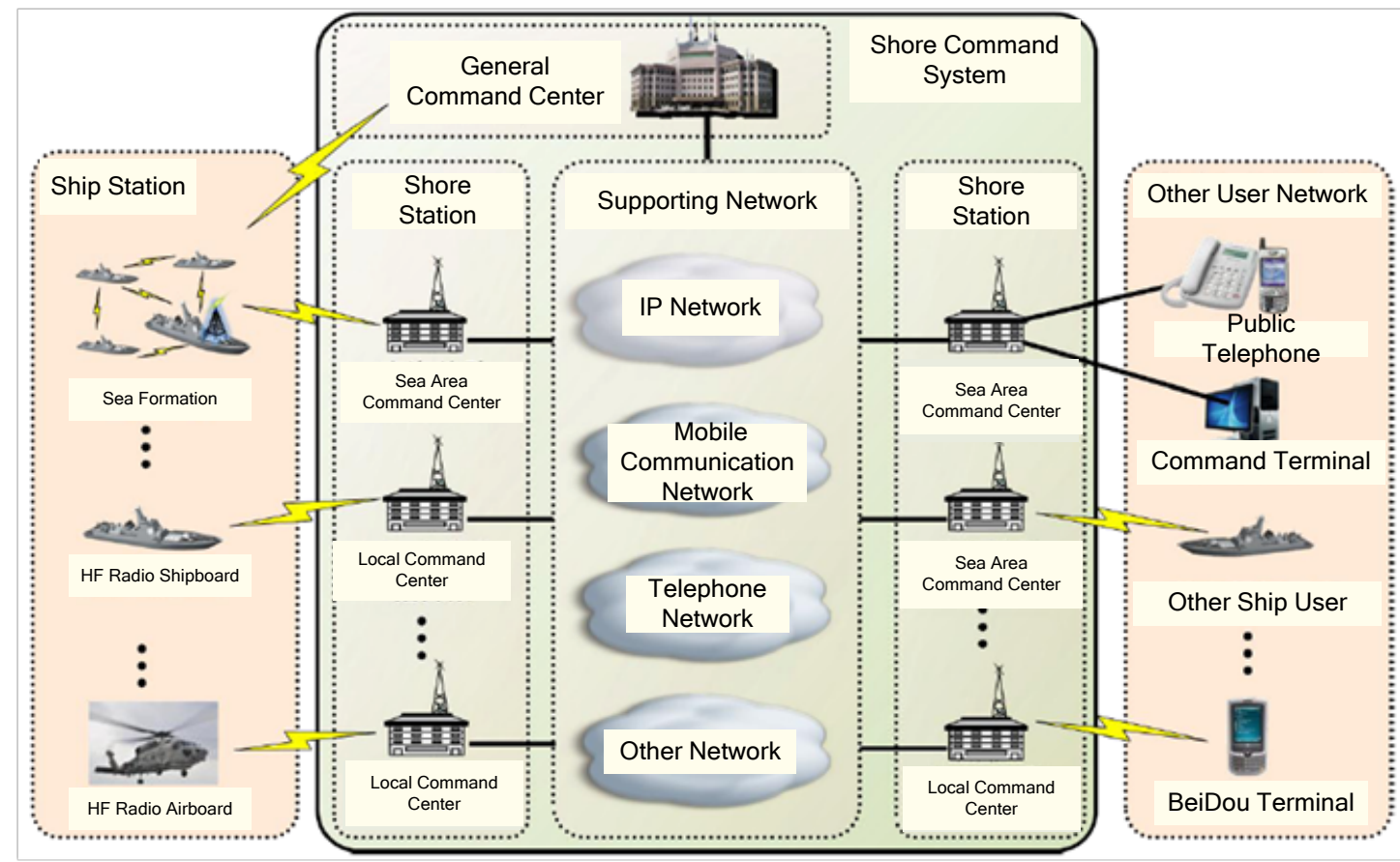

Fig.6. Schematic Diagram Of Shortwave Shore Access Network System

Between the commander Center, the major sea command center, and province / city command center and shortwave station, they form a wired and wireless integrated use of short-wave shore sea remote communication network of ground support through the IP bearing network, telephone network and private network interconnection.

Shortwave station is the shortwave transmitter site of the command center, It can provide for the command center and slipway, Sea Fleet Command Center for voice, SMS, e-mail and fax contact shortwave transmission service. National shortwave coast station forms an adaptive, multipoint and a wide range of coverage in national area. Berth, sea fleet command center can automatically choose the coast station connected to the ground network, to achieve real-time information and at all levels of command center contact.

\section{Sea Fleet Communication}

Integrated use of VHF, UHF radio, satellite radio communications, such as building more access, more comprehensive, multi-channel transmission and multiple hops relay business integrated wireless transmission platform, a broadband transmission resources, support channel resources on demand, which can realize information transmission over a long distance air and water.System is indicated as shown in figure 7. 


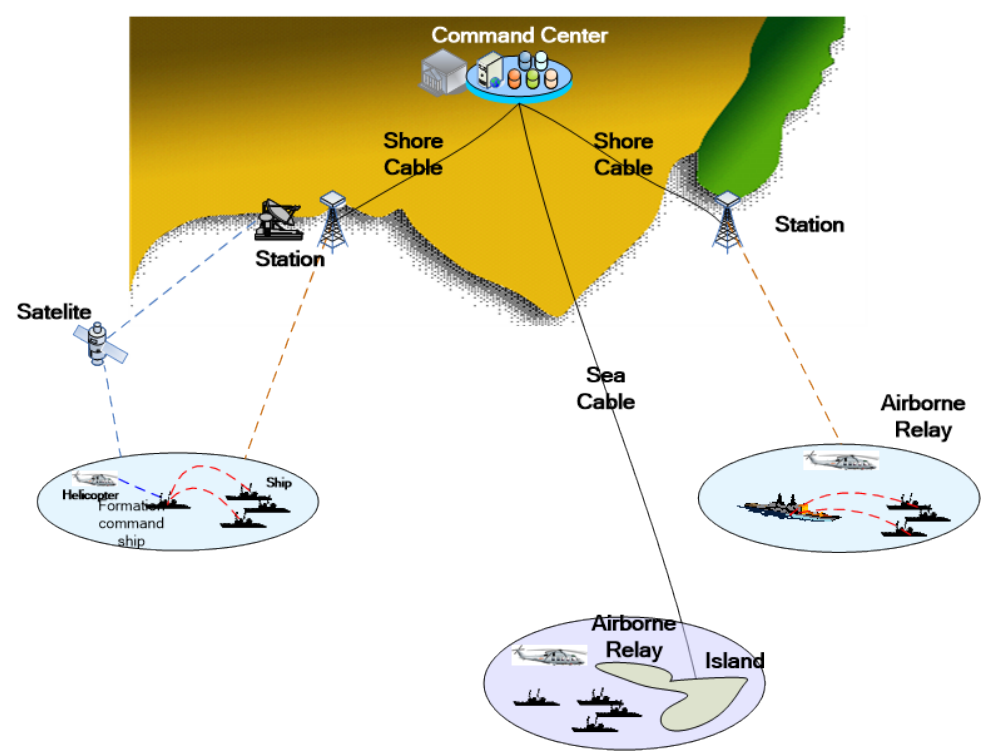

Fig.7. Formation Of Communication System

This system adopts high speed digital radio, ultra-short wave radio two electricity network construction of fleet network, including: electrical network of ultrashort wave narrow frequency band, anti-interference performance is better, developed using TDMA access methods, used in the voice of high real-time demand in carrying on the business operations; High-speed digital radio frequency band width, high rate, more polling access protocol, it is proposed for hosting the transmission bandwidth to demand higher video business; Or adopt improved CSMA protocol access, for hosting the common data services.

On the basis of the double layer network, can provide ultrashort wave radio access for airborne nodes, realizes the phone user and user interaction between voice and short message business ship. Fleet communication system includes the communication command ship fleet and ship fleet communication access.

A.communication command ship fleet

The ultrashort radio access function: to provide shipboard terminal VHF radio access;

The high speed data transmission radio access function: to provide high-speed data erminal/shipboard airborne radio access;

B.the formation communication access to the ship

Ultrashort wave radio access function: provide the shipboard ultrashort wave radio access terminal;

High speed digital radio access function: provide high-speed data terminal / shipboard airborne radio access.

\section{Cross Network Interconnection}

Communication command network can realize across the network to each other, Through the loop and coastal relay interface and network, cluster network is connected, the exchange of voice service implementation; Through GSM and CDMA network interface and mobile communication network such as interconnection, to realize the exchange of SMS business; Through the optical fiber cable line and military network interconnection, emergency situations to realize data exchange of business information, implemented by shortwave channel, an emergency coastguard slipway access military network for voice and SMS communication.

Across the network communication ability and coastal support in the implementation of the important tasks, can realize fleet ships and head fixed telephone, encryption, cell phone, desktop communication command terminal to realize the telephone, short information, video images and other business communications. 


\section{Summary}

Communication command integrated network can achieve a variety of technical means of the integrated and networked application of commonly used methods include shortwave, ultrashort wave, satellite, compass, etc. In system construction, comprehensive consideration hierarchical network structure, protocol interface, application of command, with the integration of design ideas to build the network, rather than by the means of communication, business communication command network independently. Communication command network is proposed to adopt the end, tubes, cloud architecture design, based on SOA on-demand service, and coastal for users with neutral access, posture review and distribution, based on the integrated service communication command ability.

\section{References}

[1] Kuisheng Feng, Jiadong Xu, Na Li. A Phased Array Antenna System for INMARSAT Mobile Ground Terminal[C]. 2009 3rd IEEE International Symposium on Microwave, Antenna, Propagation and EMC Technologies for Wireless Communications, China: Xi’an, 2009.425-427.

[2] CHEN Liang. Development of the U.S.MILSATCOM[J]. Communications Technology, 2010,47(4):354-357.

[3] THUE RME R K E. New Look at Military Satcom[J]. Military Information Technology, 2013 (01): $26-27$.

[4] STEW M. Military Space Communications Lacks Direction[J]. National Defense, 2013(01):30 $-32$.

[5] RON B. Desegregation and Diversification of U.S. MILSATCOM[J]. Milsat Magazine, 2012 (04): 64-71.

[6] ZHOU Zhi chao, ZHANG Mei xu. Analysis on characteristics of operational commanding and commanding information system of American aircraft carrier battle groups[J]. SHIP SCIENCE AND TECHNOLOGY,2011,33(11):140-144.

[7] HOU Xiao-peng,TAN Xian-chun. Assistant Data Communication with Shipborne Aircraft[J]. Chinese Journal of Ship Research,2010,5(2):30-32. 